\title{
Pengaruh Harga dan Store Atmosphere terhadap Kepuasan Konsumen pada Café Dreamblack Coffee Mojokerto
}

\author{
M. Syamsul Hidayat \\ Fakultas Ekonomi Universitas Islam Majapahit Mojokerto \\ syamshidayat@gmail.com
}

\begin{abstract}
The culinary businesses increase in the establishment such as cafes in CityMojokerto indicates that the result of market demand for the culinary field which also continues to increase. This study aims to determine the effect of Price and store atmosphere on customer satisfaction at Dream Black Coffee cafe partially and simultaneously. This research is a quantitative approach research. The population in this study is Dream Black Coffee consumers. The sampling technique uses accidental sampling technique and purposive sampling with a total sample of 125 people. Data collection techniques use a questionnaires, observation and documentation. The data analysis technique used is the classical assumption test analysis and multiple linear regression. The results show that Price and store atmosphere have a positive and significant effect on customer satisfaction in Dream Black Coffee partially, this is seen from the significant value 0.000 smaller than 0.05 with a value of $t$ count 3.831 and a positive regression coefficient of 0.221 , while the price shows a significant value of 0.000 smaller than 0.05 with a calculated value of 9,801 and a positive regression coefficient of 0.356 . While simultaneously obtained the calculated $F$ value of 53,441 with a significance value of 0.000 less than 0.05 so that it is concluded that price and store atmosphere simultaneously have a positive and significant effect on customer satisfaction.
\end{abstract}

\section{Keywords: Price, Store atmosphere, Consumer satisfaction.}

\section{PENDAHULUAN}

Dunia bisnis pada era globalisasi seperti saat ini telah mengalami kemajuan yang sangat pesat. Banyak sekali terjadi perubahan yang dapat dilihat dengan semakin meningkatnya gaya hidup, pola pikir masyarakat dan kemajuan teknologi yang ada. Dampak dari adanya perubahan serta kemajuan tersebut masyarakat dituntut untuk mengimbanginya. Berkaitan dengan hal tersebut juga terajdi perkembangan gaya hidup yang semakin modern dari perilaku konsumen dalam mementukan keputusan pembelian suatu produk juga ikut beragam. Saat ini begitu banyak produk dan jasa yang menawarkan keunggulan dan keunikannya masing-masing. Dan hal itu mengakibatkan konsumen menjadi banyak pilihan dalam menggunakan jasa dan membeli produk yang ditawarkan oleh produsen. Dengan keadaan tersebut produsen juga harus berupaya untuk memahami keinginan, kebutuhan dan permintaan para konsumen, serta menciptakan inovasiinovasi baru yang yang berbeda dari perusahaan sejenis lainya. Oleh karena itu produsen harus mampu membuat konsumen merasa puas dengan produk maupun jasa yang ditawarkan. Menurut Kotler (2012:13) Kepuasan pelanggan adalah

Bisman (Bisnis \& Manajemen): The Journal Of Business and Management 
perasaan senang atau kecewa seseorang yang muncul setelah membandingkan antara persepsi atau kesan terhadap kinerja atau hasil suatu produk dan harapan harapannya. Kondisi persaingan yang ketat dalam dunia usaha membuat para pelaku usaha dituntut untuk mampu bertahan dan bersaing dengan para pesaingnya,.

Dewasa ini berbagai macam jenis usaha yang dapat menjadi peluang dalam dunia usaha, tak terkecuali dengan usaha cafe. Eksistensi cafe di kota Mojokerto sudah bisa di bilang sangat berkembang dan menjadi pemandangan sehari-hari bagi masyarakat. Beragam nama cafe, jenis makanan dan minuman yang ditawarkan mulai dari konsep tradisional sampai modern, dan hal inilah sebagai era baru di bidang kuliner khususnya cafe. Meningkatnya pendirian usaha kuliner seperti cafe di kota Mojokerto menandakan bahwa hasil dari permintaan pasar terhadap bidang kuliner yang juga terus meningkat. Hal ini seringkali di kaitkan dengan mobilitas masyarakat yang semakin tinggi serta aktivitas yang padat mengakibatkan semakin banyak masyarakat menghabiskan waktu diluar rumah untuk mencari sesuatu yang bersifat praktis dan menyenangkan untuk memenuhi kebutuhan diri.

Harga adalah jumlah uang yang ditagihkan untuk suatu produk atau sejumlah nilai yang dipertukarkan konsumen untuk manfaat memiliki atau menggunakan produk (Daryanto (2013). Hal ini berarti bahwa harga merupakan sejumlah uang yang akan dikeluarkan oleh konsumen untuk mendapat barang atau jasa yang dinginkan. Konsumen akan sangat sensitif mengenai harga karena konsumen akan membandingkan harga dengan apa yang didapat.Penciptaan atmosphere (suasana) yang baik juga di dukung desain interior yang unik serta tersedianya berbagai fasilitas penunjang seperti wifi, musik live dan sebagainya merupakan daya tarik yang sangat penting bagi konsumen. Menurut Kotler \& Keller (2012:61) menyatakan store atmosphere adalah desain lingkungan melalui komunikasi visual, pencahayaan, warna, music, dan wangi-wangian untuk merancang respon emosional dan persepsi pelanggan dan untuk mempengaruhi pelanggan dalam membeli produk. Selain store atmosphere (suasana toko), yang harus diperhatikan oleh setiap perusahaan dalam bersaing, terutama usaha dalam bidang kuliner yaitu kebijakan penetapan harga. Berdasarkan penjelasan tersebut, untuk itu penulis merasa tertarik untuk mengambil judul penelitian pengaruh harga dan store atmosphere terhadap kepuasan konsumen pada Dreamblack Coffee Mojokerto)

\section{Tujuan Penelitian}

a. Untuk mengetahui pengaruh harga dan store atmosphere, secara parsial terhadap kepuasan konsumen di Cafe Dream Black coffee.

b. Untuk mengetahui pengaruh harga dan store atmosphere, terhadap kepuasan konsumen di Cafe Dream Black coffee. 


\section{TINJAUAN PUSTAKA}

Harga

Menurut Kotler dan Armstrong (2014:312) yang dimaksud harga adalah "The amount of money charged for a product or service, the sum of the values thet customers exchange for the benefit of having or using the product or service".

\section{Store Atmosphere}

Menurut Kotler \& Keller (2012:61) menyatakan store atmosphere adalah desain lingkungan melalui komunikasi visual, pencahayaan, warna, music, dan wangi-wangian untuk merancang respon emosional dan persepsi pelanggan dan untuk mempengaruhi pelanggan dalam membeli produk.

\section{Kepuasan Konsumen}

Kepuasan konsumen menurut Kotler \& Keller yang dialih bahasakan oleh Bob Sabran (2012:117) sebagai perasaan suka atau tidak seseorang terhadap suatu produk setelah ia membandingkan prestasi produk tersebut dengan harapannya.

\section{Kerangka Pemikiran}

Kerangka berfikir ini dinyatakan sebagai berikut:

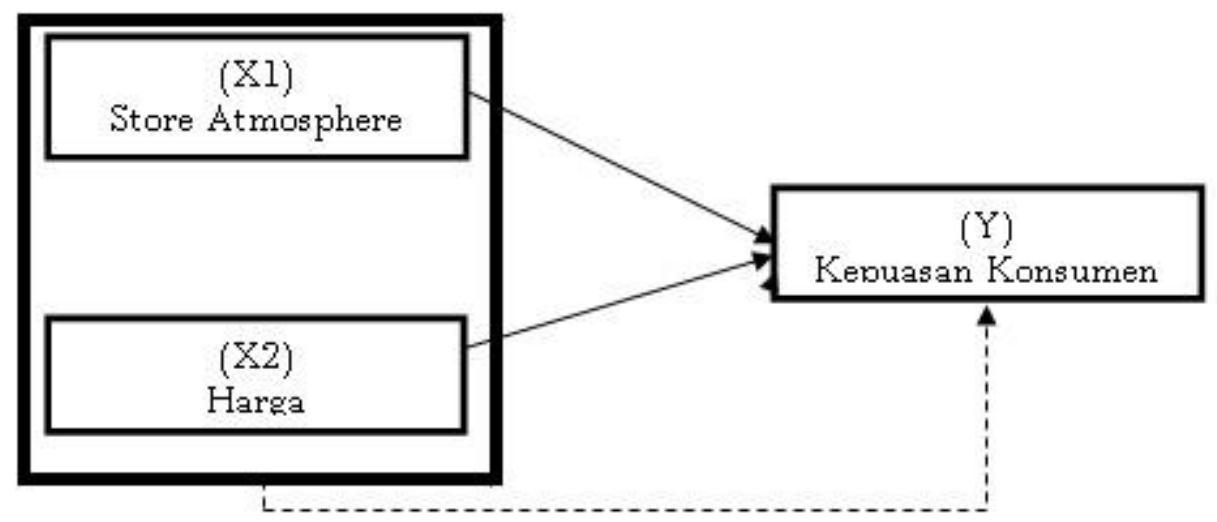

Gambar 1. Kerangka pemikiran

Keterangan :

$\longrightarrow$ : Pengaruh secara parsial

$\rightarrow$ : Pengaruh secara simultan

\section{Hipotesis}

Berdasarkan deskripsi teoritis, hasil-hasil penelitian yang relevan, dan kerangka pemikiran di atas, maka dapat dirumuskan hipotesis penelitian sebagai berikut:

H1 : Diduga Harga dan Store atmosphere berpengaruh secara parsial terhadap kepuasan konsumen di Cafe Dreamblack coffee.

H2 : Diduga Harga dan Store atmosphere berpengaruh secara simultan terhadap kepuasan konsumen di Cafe Dreamblack coffee.

\section{METODE PENELITIAN}

Bisman (Bisnis \& Manajemen): The Journal Of Business and Management 


\section{Desain Penelitian}

Adapun Jenis penelitian yang digunakan adalah deskriptif kuantitatif yang bertujuan untuk mengetahui gambaran tentang pengaruh Harga dan Store atmosphere terhadap kepuasan konsumen Cafe Dream Black coffee yang berupa hasil kuisioner yang dibagikan ke responden. Penelitian deskriptif dimaksudkan untuk mengetahui apa adanya suatu variabel, gejala atau keadaan. Pendekatan kuantitatif mementingkan adanya variabel-variabel yang di definisikan dalam bentuk operasionalisasi variabel masing-masing. Variabel bebas dalam penelitian ini yaitu harga (X1) dan store atmosphere (X2), Variabel terikat yang digunakan dalam penelitian ini adalah kepuasan konsumen (Y). Jenis data yang digunakan pada penelitian ini adalah data kuantitatif. Sumber data yang digunakan dalam penelitian ini yaitu data primer. Data primer yaitu data yang diperoleh secara langsung, tidak memakai perantara dari sumber asli. Teknik pengumpulan data pada penelitian ini yaitu dengan menggunakan metode kuesioner, obsevasi dan wawancara.

\section{Waktu dan Tempat Penelitian}

Waktu dalam penelitian ini pada bulan Juni sampai dengan bulan Juli 2018. Dalam penelitian ini yang digunakan sebagai objek penelitian yaitu pada Cafe Dream Black coffee yang beralamatkan di Jalan Empunala No 208, Kelurahan Balongsari, Kecamatan Magersari, Kota Mojokerto, Kode Pos 61318.

\section{Populasi dan Sampel}

Populasi dalam penelitian ini yaitu konsumen cafe Dream Black coffee setiap hari minggu pada bulan juni 2018, dan pengambilan hari minggu pada penelitian ini dikarenakan pada akhir pekan konsumen di Dream Black Coffee lebih ramai di bandingkan hari-hari biasa, dan akan lebih efektif karena lebih mudah mendapatkan responden yang sesuai dengan kriteria dalam penelitian ini. Dengan perkiraan jumlah populasi dalam penelitian ini yaitu 185 konsumen. Sedangkan sampel adalah bagian dari jumlah dan karakteristik yang dimiliki oleh populasi tersebut (Sugiyono 2013:116). Sampel diambil dari jumlah populasi dan pada penelitian ini digunakan tingkat kesalahan yang dapat ditolerir yaitu sebesar $5 \%$. Penentuan ukuran sampel responden pada penelitian ini menggunakan rumus Slovin,Dengan tingkat kesalahan yang dapat ditolerir sebesar 5\% (0,05), maka diperoleh ukuran sampel (n) pada penelitian ini sebanyak 125 orang konsumen cafe Dreamblack coffee yang akan dijadikan sebagai ukuran sampel penelitian.

Teknik pengambilan sampel pada penelitian ini adalah menggunakan metode Accidental, dimana metode Accidental Sampling yaitu untuk memperoleh data peneliti menemui responden yaitu orang-orang yang secara tidak sengaja dijumpai saat berkunjung di tempat pnelitian Dan dengan kriteria-kriteria tertentu untuk dijadikan sampel. Kriteria-kriteria tersebut adalah pengunjung yang telah melakukan kunjungan dan pembelian di Dream Black Coffee lebih dari 1 kali dalam jangka waktu 1 bulan agar mampu memberikan informasi yang baik dan benar.

Bisman (Bisnis \& Manajemen): The Journal Of Business and Management 


\section{INSTRUMEN PENELITIAN Uji Validitas}

Uji validitas adalah untuk mengukur valid atau tidaknya suatu kuesioner. Menurut Sugiyono (2013:172) penelitian yang valid yaitu hasil penelitian yang memiliki kesamaan antara data yang terkumpul dan data yang sesungguhnya terjadi pada objek yang diteliti. Instrumen yang valid berarti instrumen tersebut layak digunakan untuk mengukur apa yang seharusnya diukur. Besarnya $r$ hitung dapat dihitung dengan menggunakan korelasi dengan taraf signifikan $(\alpha)=0.05$ jika $r$ hitung lebih besar dari $r$ tabel maka kuesioner yang digunakan sebagai alat ukur dapat dinyatakan valid.

\section{Uji Reliabilitas}

Reliabilitas adalah indeks yang menunjukkan sejauh mana suatu alat ukur dapat dipercaya. Uji reliabilitas adalah suatu cara untuk melihat apakah alat ukur yang berupa kuesioner yang digunakan konsisten atau tidak. Apabila suatu alat pengukur dipakai dua kali atau lebih dan hasil pengukuran yang diperoleh konsisten, maka alat ukur tersebut reliabel.

Skala dikelompok ke dalam lima kelas dengan renge yang sama, maka ukuran kemantapan alpha dapat diinterprestasikan sebagai berikut (Juliansyah Noor, 2012: 165):

1. Cronbach alpha 0,00 s.d. 0,20 , artinya tidak reliabel

2. Cronbach alpha 0,21 s.d. 0,40 , artinya kurang reliabel

3. Cronbach alpha 0,42 s.d. 0,60 , artinya cukup reliabel

4. Cronbach alpha 0,61 s.d. 0,80 , artinya reliabel

5. Cronbach alpha 0,81 s.d. 1,00, artinya sangat reliabel

\section{TEKNIK ANALISIS DATA}

\section{Uji Asumsi Klasik}

\section{Uji Normalitas}

Uji normalitas adalah untuk mengetahui apakah variabel dalam penelitian memiliki sebaran distribusi normal atau tidak. Untuk menguji normalitas residual digunakan grafik P-Plot dengan kriteria jika data menyebar disekitar garis diagonal dan mengikuti garis diagonal bisa dikatakan bahwa dalam regresi ini sudah memnuhi uji asumsi normalitas.

2. Uji Multikolonieritas

Uji Multikolineritas bertujuan untuk menguji apakah model regresi ditemukan adanya korelasi antar variabel bebas (independen). Untuk menguji Multikolineritas dengan cara melihat nilai VIF masing-masing variabel independen, jika nilai $\mathrm{VIF}<10$, maka dapat disimpulkan data bebas dari gejala Multikolineritas

\section{Regresi Berganda}

Analisis tersebut digunakan untuk mengetahui seberapa besar pengaruh variabel bebas yaitu: harga (X1))dan store atmosphere (21), terhadap variabel terikat yaitu kepuasan konsumen (Y).

Persamaan regresi linier berganda adalah sebagai berikut :

Bisman (Bisnis \& Manajemen): The Journal Of Business and Management 


$$
\mathrm{Y}=\mathrm{a}+\mathrm{b}_{1} \mathrm{x}_{1}+\mathrm{b}_{2} \mathrm{x}_{2}
$$

Keterangan :

$\mathrm{y}=$ Variabel dependen (kepuasan konsumen)

$\mathrm{a}=$ Konstanta

$\mathrm{b}_{1}=$ Koefisiensi regresi harga

$\mathrm{b}_{2}=$ Koefisiensi regresi store atmosphere

$\mathrm{x}_{1}=$ Variabel harga

$\mathrm{x}_{2}=$ Variabel store atmosphere

\section{Uji Hipotesis}

\section{Uji t}

Uji $\mathrm{t}$ adalah analisis untuk menguji pengaruh variabel independen secara parsial terhadap variabel dependen. Pengujian dilakukan dengan menggunakan tingkat signifikan $0,05(\alpha=5 \%)$. Penerimaan atau penolakan hipotesis dapat dilakukan dengan kriteria :

1)

Jika nilai signifikan $>0,05$ maka hipotesis ditolak (koefisien regresi tidak signifikan). Ini berarti secara parsial variabel independen tidak mempunyai pengaruh secara signifikan terhadap variabel dependen.

2) Jika nilai signifikan $\leq 0,05$ maka hipotesis diterima (koefisien regresi signifikan). Ini berarti secara parsial variabel independen mempunyai pengaruh yang signifikan terhadap variabel dependen.

\section{Uji F}

Uji $\mathrm{F}$ digunakan untuk mengetahui apakah semua variabel independen mempunyai pengaruh secara simultan terhadap variabel dependen. Untuk pengujian pada penelitian ini dilakukan dengan menggunakan uji signifikansi. Jika nilai signifikansi lebih kecil dari 0,05 , maka ini berarti ada alasan yang untuk menerima hipotesis satu $\left(\mathrm{H}_{1}\right)$ dan menolak hipotesis nol $\left(\mathrm{H}_{0}\right)$, demikian pula sebaliknya.

\section{Koefisien Determinasi}

Koefisien determinasi $\mathrm{R}^{2}$ pada intinya menguji seberapa jauh kemampuan model dalam menerangkan variasi variabel dependen. Cara menentukan koefisien determinasi dengan melihat kolom R Square, hasil dari analisa SPSS. 


\section{HASIL DAN PEMBAHASAN}

\section{Hasil Uji Validitas}

Tabel 5

Hasil Uji Validitas Harga,Store Atmosphere, dan Kepuasan Konsumen

\begin{tabular}{ccccc}
\hline Variabel & Item & $\begin{array}{c}\text { r } \\
\text { hitung }\end{array}$ & r tabel & Keterangan \\
\hline Harga & H1 & 0,659 & 0,173 & Valid \\
& H2 & 0,822 & 0,173 & Valid \\
& H3 & 0,762 & 0,173 & Valid \\
Store & H4 & 0,744 & 0,173 & Valid \\
Atmosphere & SA 1 & 0,539 & 0,173 & Valid \\
& SA 2 & 0,490 & 0,173 & Valid \\
& SA 3 & 0,503 & 0,173 & Valid \\
& SA 4 & 0,675 & 0,173 & Valid \\
& SA 5 & 0,537 & 0,173 & Valid \\
& SA 6 & 0,568 & 0,173 & Valid \\
& SA 7 & 0,670 & 0,173 & Valid \\
& SA 8 & 0,527 & 0,173 & Valid \\
& SA 9 & 0,561 & 0,173 & Valid \\
& & & & \\
Kepuasan & KK 1 & 0,484 & 0,173 & Valid \\
Konsumen & KK 2 & 0,325 & 0,173 & Valid \\
& KK 3 & 0,722 & 0,173 & Valid \\
& KK 4 & 0,749 & 0,173 & Valid \\
& KK 5 & 0,710 & 0,173 & Valid \\
\hline
\end{tabular}

Berdasarkan tabel 5, seluruh item pertanyaan variabel independen dan variabel dependen dalam instrumen penelitian dinyatakan valid, karena $\mathrm{r}$ hitung > 0,173 .

\section{Hasil Uji Reliabilitas}

Tabel 6

Hasil Uji reliabilitas Harga, Store Atmosphere, Harga, dan Kepuasan Konsumen

\begin{tabular}{cccc}
\hline Variabel & Cronbach's Alpha & N of Items & Keterangan \\
\hline Harga & 0,735 & 4 & Reliabel \\
Store Atmosphere & 0,731 & 9 & Reliabel \\
Kepuasan & 0,544 & 5 & Cukup Reliabel \\
Konsumen & & & \\
\hline
\end{tabular}

Bisman (Bisnis \& Manajemen): The Journal Of Business and Management 


\section{Uji asumsi klasik}

1. Hasil Uji Normalitas

Gambar 2

Hasil Uji Normalitas

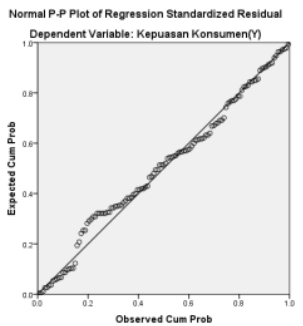

Dari grafik diatas dapat diketahui bahwa distribusi data telah mengikuti garis diagonal antara 0 (nol) dengan pertemuan sumbu Y dengan sumbu X. Hal ini menunjukkan bahwa data dalam penelitian ini telah berdistribusi normal. Dengan demikian dapat disimpulkan bahwa pendekatan grafik model regresi telah memenuhi asumsi normalitas.

2. Hasil Uji Multikolonieritas

Tabel 7

Hasil Uji Multikoliniearitas

\begin{tabular}{ccc}
\hline Variabel & \multicolumn{2}{c}{ Colinearitas Statistics } \\
\cline { 2 - 3 } Harga & Tolerance & VIF \\
Store Atmosphere & 0,997 & 1,003 \\
\hline
\end{tabular}

Berdasarkan tabel 7 koefisien diatas diperoleh nilai tolerance dari variabel harga (X2) 0,997 > 0,1 dan VIF 1,003 < 10,store atmosphere (X1) 0,996>0,1 dan VIF $1,003<10$, semua nilai tolerance menunjukan bahwa nilai tolerance diatas 0,1 dan nilai VIF dari variabel terikatnya menunjukan bahwa nilai VIF < 10. Maka dapat disimpulkan bahwa korelasi koefisien antar variabel terikat menunjukan tidak ada gangguan multikolinearitas sehingga data layak diteliti.

\section{Hasil Regresi Berganda}

Tabel 8

Hasil Analisis Regresi Berganda

Coefficientsa

\begin{tabular}{|c|c|c|c|}
\hline \multicolumn{3}{|c|}{$\begin{array}{l}\text { Unstandardize standardized } \\
\text { d Coefficients Coefficients }\end{array}$} & \\
\hline $\mathrm{B}$ & $\begin{array}{l}\text { Std. } \\
\text { Error }\end{array}$ & Beta & \\
\hline
\end{tabular}

Bisman (Bisnis \& Manajemen): The Journal Of Business and Management 


\begin{tabular}{llllll}
\hline (Constant) & 3.569 & 1.387 & & 2.572 & .011 \\
& & & & & \\
Harga (X1) & .221 & .058 & .254 & 3.831 & .000 \\
Store Atmosphere & .356 & .036 & .649 & 9.801 & .000 \\
(X2) & & & & & \\
\hline
\end{tabular}

a. Dependent Variable: Kepuasan_Konsumen

Dari hasil pengolahan data pada tabel 8 , di peroleh persamaan regresi nya adalah:

$$
\mathrm{Y}=3.569+0, .221 \mathrm{X} 1+0,356 \mathrm{X} 2
$$

Berdasarkan pada model persamaan regresi diatas, dapat disimpulkan sebagai berikut :

1) Berdasarkan nilai konstanta sebesar 3.569, Hal ini menunjukkan bahwa pada saat harga (X1), dan store atmosphere (X1) dianggap tetap (konstan), kepuasan konsumen (Y) menurun sebesar 3.569satuan.

2) Koefisien regresi store atmosphere

Nilai koefisien regresi store atmosphere sebesar 0, 356 nilai koefisien regresi ini bersifat positif yang menunjukkan adanya hubungan searah antara variabel store atmosphere dengan variabel kepuasan konsumen. Hal ini mengindikasi bahwa apabila store atmosphere (X1) naik 1 satuan, maka kepuasan konsumen (Y) juga akan mengalami peningkatan sebesar 0, 356 satuan.

3) Koefisien regresi harga

Nilai koefisien regresi harga sebesar 0,246, nilai koefisien regresi ini bersifat positif yang menunjukkan adanya hubungan searah antara variabel harga dengan variabel kepuasan konsumen. Hal ini mengindikasi bahwa apabila harga (X2) naik 1 satuan, maka kepuasan konsumen (Y) juga akan mengalami peningkatan sebesar 0,246 satuan.

\section{Hasil Pengujian Hipotesis}

\section{Uji t}

Tabel 9

hasil uji t (parsial)

\begin{tabular}{ccll}
\hline Variabel & B & t & Sig. \\
\hline Harga $(\mathbf{X} 1)$ & 0.221 & 3.831 &, 000 \\
Store atmosphere $(\mathbf{X} 2)$ & 0,356 & 9.801 &, 000 \\
\hline
\end{tabular}

Berdasarkan tabel dari hasil uji t disimpulkan :

1) Harga berpengaruh terhadap kepuasan konsumen.

Variabel harga berpengaruh secara positif dan signifikan terhadap kepuasan konsumen, hal ini terlihat dari nilai signifikan 0.000 lebih kecil dari 0.05 dengan nilai t hitung 3.831dan koefisien regresi bernilai positif sebesar 0.221. Maka dapat disimpulkan harga mempunyai pengaruh positif dan signifikan terhadap kepuasan konsumen di cafe Dream Black Coffee.

Bisman (Bisnis \& Manajemen): The Journal Of Business and Management 
2) Store Atmosphere berpengaruh terhadap kepuasan konsumen.

Variabel store atmosphere berpengaruh secara positif dan signifikan terhadap kepuasan konsumen, hal ini terlihat dari nilai signifikan 0.000 lebih kecil dari 0.05 dengan nilai $\mathrm{t}$ hitung 9.801dan koefisien regresi bernilai positif sebesar 0.356. Maka dapat disimpulkan store atmosphere mempunyai pengaruh yang positif dan signifikan terhadap kepuasan konsumen di cafe Dream Black Coffee

\section{Uji F}

\section{Tabel 10 Hasil Uji F}

ANOVA ${ }^{\mathrm{a}}$

\begin{tabular}{|c|c|c|c|c|c|c|}
\hline Mode & & $\begin{array}{l}\text { Sum of } \\
\text { Squares }\end{array}$ & df & $\begin{array}{l}\text { Mean } \\
\text { Square }\end{array}$ & $\mathrm{F}$ & Sig. \\
\hline \multirow[t]{3}{*}{1} & $\begin{array}{l}\text { Regressio } \\
\mathrm{n}\end{array}$ & 337.625 & 2 & 168.812 & 53.441 &, $000^{\mathrm{b}}$ \\
\hline & Residual & 385.382 & 122 & 3.159 & & \\
\hline & Total & 723.008 & 124 & & & \\
\hline
\end{tabular}

a. Dependent Variable: Kepuasan_Konsumen

b. Predictors: (Constant), Harga, Store_Atmosphere

Berdasarkan tabel di atas (uji Anova), diperoleh nilai $\mathrm{F}$ hitung sebesar 53.441 dengan tingkat probabilitas 0,000 (signifikansi). Karena lebih kecil dari 0,05, maka model regresi dapat digunakan untuk memprediksi kepuasan konsumen atau dengan kata lain bahwa harga dan store atmosphere secara simultan mempunyai pengaruh yang signifikan terhadap kepuasan konsumen.

\section{Koefisien Determinasi}

Tabel 11

Hasil Uji Koefisien Determinasi

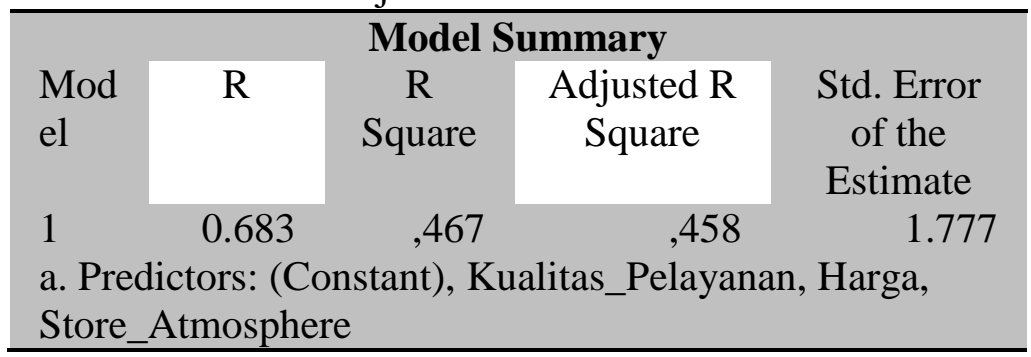

Berdasarkan tabel 6 hasil uji koefisien determinasi dapat dilihat bahwa nilai $R$ Square sebesar 0,467 , yang artinya variabel harga dan store atmosphere, mampu menjelaskan kepuasan konsumen sebesar 46,7\%, dan sisanya sebesar $53,3 \%$ dijelaskan oleh faktor lain di luar variabel dalam penelitian ini.

\section{PEMBAHASAN}

\section{Pengaruh Harga Terhadap Kepuasan Konsumen.}

Bisman (Bisnis \& Manajemen): The Journal Of Business and Management 
Pengujian variabel harga menghasilkan harga berpengaruh positif terhadap kepuasan konsumen. Hal ini dibuktikan dengan nilai $t$ hitung sebesar 3.831dengan nilai signifikansi sebesar 0.000 lebih kecil dari toleransi kesalahan $\alpha=0.05$. Nilai koefisien regresi sebesar 0.221 yang memiliki arah positif mengindikasikan bahwa pada tingkat harga tertentu, apabila manfaat yang dirasakan konsumen Dream Black Coffee meningkat, maka nilainya akan meningkat. Dengan demikian, apabila nilai yang dirasakan konsumen Dream Black Coffee semakin tinggi, maka akan menciptakan kepuasan konsumen.

Daryanto (2013), harga adalah jumlah uang yang ditagihkan untuk suatu produk atau sejumlah nilai yang dipertukarkan konsumen untuk manfaat memiliki atau menggunakan produk. Hal ini berarti bahwa harga merupakan sejumlah uang yang akan dikeluarkan oleh konsumen untuk mendapat barang atau jasa yang dinginkan. Konsumen akan sangat sensitif mengenai harga karena konsumen akan membandingkan harga dengan apa yang didapat. Murah atau mahalnya harga suatu produk atau jasa sifatnya relatif. Harga yang terlalu tinggi tanpa diimbangi dengan kualitas yang baik maka dapat menimbulkan kekecewaan konsumen. Dengan demikian, dalam menetapkan harga, pemilik usaha harus menyesuaikan harga dengan kualitas produk atau jasa yang ditawarkan. Selain itu, pemilik usaha juga perlu membandingkan harga yang ditetapkan dengan harga produk atau jasa serupa yang diproduksi atau ditawarkan oleh pesaing. Hal ini dimaksudkan agar harga yang ditentukan oleh perusahaan tersebut tidak terlalu tinggi atau sebaliknya.

Setiap usaha dalam bidang kuliner pasti memiliki kelebihan dan kekurangan masing-masing, baik dari segi tempat, fasilitas, menu, dan tentunya harga yang ditawarkan. Pemilik Dream Black Coffee harus pandai dalam menghitung laba sehingga dapat menetapkan harga makanan dan minuman dengan tepat agar konsumen tidak merasa kemahalan. Harga yang ditetapkan Dream Black Coffee juga harus disesuaikan dengan kualitas produk atau jasa yang ditawarkan. Hal ini akan membuat konsumen yang berkunjung ke Dream Black Coffee merasa puas.

\section{Pengaruh Store Atmophere Terhadap Kepuasan Konsumen.}

Diketahui dari hasil penelitian store atmosphere berpengaruh positif terhadap kepuasan konsumen. Hal ini dibuktikan dengan nilai t hitung sebesar 9,801 dengan nilai signifikansi sebesar 0.000 lebih kecil dari toleransi kesalahan $\alpha=0.05$. Nilai koefisien regresi sebesar 0,356 yang memiliki arah positif mengindikasikan bahwa semakin baik store atmosphere maka semakin tinggi kepuasan konsumen.

Menurut Kotler \& Keller (2012:61) menyatakan store atmosphere adalah desain lingkungan melalui komunikasi visual, pencahayaan, warna, music, dan wangi-wangian untuk merancang respon emosional dan persepsi pelanggan dan untuk mempengaruhi pelanggan dalam membeli produk. Penciptaan atmosphere (suasana) dan pelayanan yang baik juga di dukung desain interior yang unik serta tersedianya berbagai fasilitas penunjang seperti wifi, musik live dan sebagainya merupakan daya tarik tersendiri bagi konsumen.

Bisman (Bisnis \& Manajemen): The Journal Of Business and Management 
Dream Black Coffee telah melakukan beberapa hal untuk menciptakan suasana toko yang baik, yaitu Dream Black Coffee telah mampu memberikan desain internal dan eksternal toko sesuai selera anak muda, memberikan musik, pengharum ruangan dan kebersihan cafe yang terjaga. Dengan penciptaan store atmosphere yang baik diharapkan pelanggan akan setia dan akan datang kembali serta tidak beralih ke tempat lain.

3. Pengaruh harga dan Store Atmosphere, Terhadap Kepuasan Konsumen.

Hasil uji F menunjukkan bahwa variabel independen yang terdiri dari store atmosphere, harga dan kualitas pelayanan secara simultan berpengaruh terhadap kepuasan konsumen sebesar 53.441 dengan nilai signifikan 0.000. Oleh karena signifikansi kurang dari 0.05 sehingga dapat disimpulkan bahwa harga dan store atmosphere, secara simultan mempunyai pengaruh yang signifikan terhadap kepuasan konsumen. Hal ini menunjukkan bahwa semakin tinggi Harga dan store atmosphere, maka semakin tinggi kepuasan konsumen. Dari hasil penelitian juga diketahui nilai koefisien determinasi sebesar 0,467 yang artinya harga dan store atmosphere, menjelaskan kepuasan konsumen sebesar $46,7 \%$, dan sisanya sebesar $53,3 \%$ dijelaskan oleh faktor lain di luar variabel dalam penelitian ini.

Harga dan Store atmosphere di desain oleh perusahaan agar dapat memberikan kepuasan kepada para konsumen. Apabila harga yang di tetapkan sesuai bagi konsumen dan store atmosphere sudah tertata dengan baik dan membuat nyaman konsumen, maka akan memberikan kepuasan tersendiri bagi konsumen. Sebaliknya jika harga dan store atmosphere, yang kurang baik bagi konsumen maka menurunkan kepuasan yang dirasakan oleh konsumen.. Sehingga berakibat Konsumen bukan hanya tidak berminat untuk melakukan pembelian tetapi konsumen tidak akan kembali lagi mengunjungi cafe tersebut.

\section{PENUTUP}

\section{Simpulan}

Pada penelitian ini bertujuan untuk mengetahui pengaruh harga dan store atmosphere, terhadap kepuasan konsumen baik secara parsial maupu simultan. Adapun hasil yang diperoleh setelah menyelesaikan seluruh pengujian adalah sebagai berikut :

1. Harga dan Store atmosphere secara parsial berpengaruh positif dan signifikan terhadap kepuasan konsumen. Hal ini dibuktikan dengan nilai signifikansi seluruh variabel $(\mathrm{X})$ sebesar 0.000 lebih kecil dari toleransi kesalahan $\alpha=0.05$ dan seluruh nilai koefisien regresi yang memiliki arah positif.

2. Harga dan Store atmosphere secara simultan berpengaruh positif dan signifikan terhadap kepuasan konsumen. Hal ini dibuktikan dengan hasil uji $\mathrm{F}$ diperoleh nilai $\mathrm{F}$ hitung sebesar 53.441 dengan nilai signifikan 0.000 lebih kecil dari dari toleransi kesalahan $\alpha=0.05$.

\section{Saran}

Berdasarkan hasil penelitian, berikut ini diberikan beberapa saran antara lain:

a. Harga pada Dream Black Coffee

Bisman (Bisnis \& Manajemen): The Journal Of Business and Management 
Manajemen Dream Black Coffe harus tetap mempertahankan dan meningkatkan manfaat yang telah diberikan kepada konsumen terhadap pengeluaran yang konsumen lakukan, agar konsumen senantiasa untuk terus mengunjungi Dream Black Coffee. Dan ada baiknya mengevaluasi kembali untuk setiap item harga makanan dan minuman bila ada kenaikan setiap tahunnya, agar konsumen yang sudah sering mengunjungi Dream Black Coffee tidak merasakan perubahan yang signifikan.

b. Store atmosphere pada Dream Black Coffee

Manajemen Dream Black Coffee disarankan untuk meningkatkan store atmosphere yang lebih baik dan sesuai selera konsumen yang dapat berpengaruh terhadap kepuasan konsumennya. Layout yang menarik, Aroma dan musik yang nyaman, pencahayaan yang tepat serta tata ruang yang baik dapat menciptakan kepuasan kepada konsumen supaya kedepannya konsumen akan bersedia untuk berkunjung dan membeli kembali untuk merasakan store atmosphere yang ada di Dream Black Coffee 


\section{DAFTAR PUSTAKA}

Daryanto. (2013). Sari Kuliah Manajemen Pemasaran. Cetakan II. Januari 2013. Bandung: PT. Sarana Tutorial Nurani Sejahtera.

Juliansyah, N. (2012). Metodelogi Penelitian. Jakarta: Kencana Prenada Media Group

Kotler, P., dan Keller, K.L. (2012). Manajemen Pemasaran. Dialih bahasakan oleh Bob Sabran, Ed 13. Jakarta: Erlangga.

\section{Erlangga.} (2012). Manajemen Pemasaran edisi 13 .Jakarta: . (2016). Marketing Management, 15th Edition. New Jersey: Pearson Internasional Edition.

Kotler, P., dan Amstrong, G. (2014). Principles of Marketing. 15th Global Edition. Pearson.

Jilid 1. Jakarta: Erlangga.

(2012). Prinsip-prinsip Pemasaran, Edisi 13,

Levy, M., dan Weitz, B. (2012). Retail Management6th edition. United States of America: McGraw-Hill International

Lupiyoadi, R. (2013). Manajemen Pemasaran Jasa. Jakarta: Salemba Empat.

Pamungkas, M. (2015). Suasana Toko Dan Promosi Penjualan Terhadap Minat Beli Konsumen Smith Buah Batu 48 Bandung. Skripsi yang dipublikasikan. Bandung : Fakultas Bisnis dan Manajemen. Universitas Widyatama.

Sugiyono. (2013). Metode Penelitian Pendidikan (Pendekatan Kuantitatif, Kualitatif, dan $R \& D)$.Bandung: Alfabeta.

Tjiptono, F. (2012). Strategi Pemasaran. Yogyakarta : Andi. - (2011). Service Management Mewujudkan Layanan Prima. Yogyakarta: ANDI Yogyakarta.

Tjiptono, F., dan Chandra, G. (2012). Pemasaran Strategik. Edisi 2. Yogyakarta:Andi Offset. 